Article

\title{
Easy Method for the Transformation of Levulinic Acid into Gamma-Valerolactone Using a Nickel Catalyst Derived from Nanocasted Nickel Oxide
}

\author{
Rut Sanchis ${ }^{1}$, Tomás García ${ }^{2}$, Ana M. Dejoz ${ }^{1}$, Isabel Vázquez ${ }^{1}$, Francisco J. Llopis ${ }^{1}$ and \\ Benjamín Solsona $1, *$ (D) \\ 1 Departament d'Enginyeria Química, ETSE-UV, Universitat de València, Av. Universitat s/n, 46100 Burjassot, \\ Valencia, Spain; rut.sanchis@uv.es (R.S.); ana.m.dejoz@uv.es (A.M.D.); isabel.vazquez@uv.es (I.V.); \\ francisco.llopis@uv.es (F.J.L.) \\ 2 Instituto de Carboquímica (ICB-CSIC), C/Miguel Luesma 4, 50018 Zaragoza, Spain; tomas@icb.csic.es \\ * Correspondence: Benjamin.solsona@uv.es; Tel.: +34-963543735
}

Received: 23 August 2019; Accepted: 6 September 2019; Published: 9 September 2019

\begin{abstract}
Different nickel catalysts have been tested for the transformation of levulinic acid into $\gamma$-valerolactone using an easy hydrothermal method, taking advantage of the properties of the high temperature water. A metallic nickel catalyst derived from $\mathrm{NiO}$ synthesized by a nanocasting procedure can achieve a productivity to $\gamma$-valerolactone, which is two orders of magnitude higher than that obtained by a commercial nickel catalyst. This nanocasted metallic nickel catalyst has shown bifunctionality as it is capable of activating water as the source for hydrogen and undertaking the further hydrogenation step. In contrast with metallic nickel, nickel oxide has shown to be incapable of transforming levulinic acid into $\gamma$-valerolactone.
\end{abstract}

Keywords: levulinic acid; valerolactone; nickel; nanocasting; hydrothermal reaction; high temperature water

\section{Introduction}

The restriction and/or ban in the use of diesel and petrol for transport is likely to take place before it was expected at the beginning of the century. In fact, in European countries, such as Norway, the UK, and Spain, the use of oil derivative fuels is projected to be banned by 2040. Different alternatives have been proposed, but those with the highest potential are electric vehicles (EVs), fuel cells vehicles, and the use of biofuels. Although bioethanol and biodiesel are widely employed biofuels, the use of cheap and abundant lignocellulosic biomass as a source for biofuels would mean a step forward in the progressive decarbonation of the automotive sector [1-4].

Among the compounds that can be obtained from the lignocellulosic biomass, we can highlight gamma-valerolactone (GVL). GVL can be obtained from the lignocellulosic biomass through the reduction and lactonization of levulinic acid (LA). LA is a fatty acid with a ketone and a carboxyl group which can be easily obtained from C6-sugars using acid catalysts (acidic hydrolysis) [5].

The transformation of LA into GVL can follow at least two pathways; firstly, LA can be hydrogenated to form a reaction intermediate, such as 4-hydroxypentanoic acid, or can be dehydrated to form anjelica lactone. Secondly, the intermediates can be cyclized/dehydrated, in the case of the 4-hydroxypentanoic acid, or reduced, in the case of anjelica lactone, to form the final GVL product $[6,7]$.

GVL is a chemical compound with high energetic density that can be used as a precursor of clean fuels or, as such, as a component for advanced green fuels [8,9]. Interestingly, GVL can be easily and safely stored and transported, since it presents relatively low flammability and is a liquid in a wide 
range of temperatures (between $-31{ }^{\circ} \mathrm{C}$ and $207^{\circ} \mathrm{C}$ ). In addition, GVL can be easily transformed into olefins and food additives or used directly as a solvent.

The interest of the GVL is manifested by the high number of publications (172 for the past 10 years), of which around 30 are related to the transformation of LA into GVL using catalysts not derived from noble metal [10]. The selective transformation of LA into GVL can be undertaken by a number of methods, involving homogeneous and/or heterogeneous catalysts. Typical materials are based on noble metals [11-17] as they are those that achieve the highest productivity to GVL. Among noble metals, those of ruthenium seem to lead to the best results [18-20]. However, as noble metals are expensive, different options involving cheaper materials have been studied. Thus, supported metal catalysts $[7,21]$ and mixed metal oxides [22,23], if properly optimized, have demonstrated to be almost as efficient as catalysts based on noble metals. Interestingly, a metal organic framework containing a zirconium catalyst has recently shown that using a continuous flow can transform methyl or ethyl levulinate into GVL. [24,25]

Catalysts based on nickel have been reported for the LA transformation to the GVL reaction as they obtain yields comparable to those obtained with noble metals and also present the advantage of being easily recovered after reaction due to the magnetic characteristics of nickel catalysts. In most cases, nickel is supported on a range of materials [26-30], such as carbon, alumina, or magnesia.

This reaction requires reduction and dehydration steps, and therefore a source of hydrogen is necessary, molecular $\mathrm{H}_{2}$ being the most frequently used. Batch systems with $\mathrm{H}_{2}$ at high pressure are the most common, although there are several studies showing that gas-phase continuous systems working at a low temperature can also selectively produce GVL [31]. As the handling of $\mathrm{H}_{2}$ is not straightforward and the flammability is high, several alternatives have been proposed to avoid the use of molecular hydrogen. The use of formic acid as a hydrogen source has been studied [32,33], showing very reasonable GVL yields. Recently, it has been reported that 0 valence inexpensive metals, such as catalysts [34-36], can transform water into hydrogen by means of a simple hydrothermal method at high pressure and mild temperatures (ca. $250^{\circ} \mathrm{C}$ ). This in situ generated hydrogen can then be used for the hydrogenation of LA into GVL at the surface of the same metals [37]. Metallic nickel together with metallic iron have been proposed as the most efficient options.

In this article we have used this very simple hydrothermal method, in which water exerts as the reaction media and also as a source of hydrogen in order to achieve the LA transformation into GVL. This method is straightforward and does not require neither gaseous hydrogen nor expensive $\mathrm{H}$-donors. Moreover, the catalysts to be employed are not based on expensive noble metals.

Thus, bulk metallic nickel catalysts have been tested. We have employed differently synthesized $\mathrm{Ni}$ based catalysts: (i) Commercial $\mathrm{Ni}$ metal, (ii) $\mathrm{Ni}$ obtained by the reduction of $\mathrm{NiO}$ from nickel nitrate, (iii) Ni derived from nickel oxide synthesized by a soft chemistry method with oxalic acid, and (iv) $\mathrm{Ni}$ derived from $\mathrm{NiO}$ synthesized by a nanocasting route.

Importantly, the catalyst derived from metal oxides prepared by a nanocasting route has resulted to give the highest yields to GVL.

\section{Materials and Methods}

\subsection{Materials}

\subsubsection{Synthesis of Nickel Catalysts}

Commercial Ni was supplied by Alfa-Aesar-150-200mesh, Kalsruhe, Germany, 99.8\%. This sample has been named NiCOM.

Standard nickel oxide was prepared by solving $\mathrm{Ni}\left(\mathrm{NO}_{3}\right)_{2} \cdot 6 \mathrm{H}_{2} \mathrm{O}$ (Sigma-Aldrich, St. Louis, $\mathrm{MO}$, USA, $>98 \%$ ) in ethanol. This solution was evaporated in a hot plate stirrer at $60^{\circ} \mathrm{C}$, dried in a furnace at $120^{\circ} \mathrm{C}$ for $12 \mathrm{~h}$, and then heat-treated in static air for $4 \mathrm{~h}$ at $500{ }^{\circ} \mathrm{C}$. This $\mathrm{NiO}$ presents a surface area of $3.4 \mathrm{~m}^{2} \mathrm{~g}^{-1}$. Before the use in the reaction, this sample was heat-treated in flowing $\mathrm{H}_{2}$ for $3 \mathrm{~h}$ at $400{ }^{\circ} \mathrm{C}$. This sample has been named NiSTD. 
A third sample was synthesized evaporating an ethanolic solution of nickel (II) nitrate (Sigma-Aldrich, $>98 \%$ ) and oxalic acid $\left(\mathrm{H}_{2} \mathrm{C}_{2} \mathrm{O}_{4} \cdot 2 \mathrm{H}_{2} \mathrm{O}\right.$, Sigma-Aldrich), being the molar Ni:oxalic ratio equal to 1:3. The evaporation of ethanol was carried out at $60^{\circ} \mathrm{C}$ in a hot plate stirrer under vigorous stirring. The paste obtained was dried for $12 \mathrm{~h}$ at $120^{\circ} \mathrm{C}$ and then heat-treated in static air in two steps; $2 \mathrm{~h}$ at $300^{\circ} \mathrm{C}$ and $2 \mathrm{~h}$ at $500{ }^{\circ} \mathrm{C}$. This nickel oxide presents a surface area of $15 \mathrm{~m}^{2} \mathrm{~g}^{-1}$. Previous to the reaction, this sample was heat-treated in flowing $\mathrm{H}_{2}$ for $3 \mathrm{~h}$ at $400{ }^{\circ} \mathrm{C}$. This sample has been named NiOXA.

Nickel oxide was also prepared by a nanocasting method using a non-solvent impregnation route with KIT-6 as a siliceous hard template. In our synthesis, $30 \mathrm{mmol}$ of $\mathrm{Ni}\left(\mathrm{NO}_{3}\right)_{2} \cdot 6 \mathrm{H}_{2} \mathrm{O}$ (Sigma-Aldrich, $>98 \%$ ) was mixed with $0.45 \mathrm{~g}$ of mesoporous silica KIT-6 (see preparation below) and was ground for a few minutes in an agate mortar. The mixture was left in a crucible and placed in a muffle furnace. The temperature was increased from ambient temperature until $500{ }^{\circ} \mathrm{C}$, using a rate of $1{ }^{\circ} \mathrm{C} \mathrm{min}-1$, and was kept at the final temperature for $5 \mathrm{~h}$. The mesoporous metal oxide was recovered by mixing the previously calcined mixture with $50 \mathrm{~mL}$ of $2 \mathrm{M} \mathrm{NaOH}$ solution. This was then stirred at $80^{\circ} \mathrm{C}$ in a hot plate stirrer for $24 \mathrm{~h}$, centrifuged, washed with ethanol-distilled water mixture, and dried in a furnace at $120^{\circ} \mathrm{C}$ overnight. The surface area of this nickel oxide was $39 \mathrm{~m}^{2} \mathrm{~g}^{-1}$. Before the reaction, this precursor was heat-treated in flowing $\mathrm{H}_{2}$ for $3 \mathrm{~h}$ at $400{ }^{\circ} \mathrm{C}$. This sample has been named NiNC.

As mentioned above, KIT- 6 is the mesoporous silica used as a hard template for the NiNC synthesis. KIT-6 mesoporous silica is a three-dimensional material with Ia3d cubic arrangement of pores. This pore structure achieves mesoporous morphologies with high thermal stability and highly crystalline walls. A KIT-6 template was prepared using acidic conditions with a mixture of butanol and Pluronic P123 triblock copolymer $\left(\mathrm{EO}_{20} \mathrm{PO}_{70} \mathrm{EO}_{20}\right)$. Pluronic P123 (12 g) was added to a solution consisting of $440 \mathrm{~g}$ of deionized water and $24 \mathrm{~g}$ of $\mathrm{HCl}(35 \%)$. This mixture was vigorously stirred at $35^{\circ} \mathrm{C}$ for $6 \mathrm{~h}$, and then $12 \mathrm{~g}$ of butanol was added and left stirring for 1 more hour. A total of $24.96 \mathrm{~g}$ of tetraethyl orthosilicate (TEOS, $98 \%$, Sigma-Aldrich) was then added at $100{ }^{\circ} \mathrm{C}$ for $24 \mathrm{~h}$. The gel obtained was then submitted to a hydrothermal treatment (static conditions) in a stainless-steel autoclave, heating at $130^{\circ} \mathrm{C}$ for $72 \mathrm{~h}$. Finally, the solid recovered by filtration was washed with deionized water and dried for $24 \mathrm{~h}$ in a furnace. The final product was then calcined in static air at $550{ }^{\circ} \mathrm{C}$ for $6 \mathrm{~h}$.

\subsubsection{Characterization Techniques}

Structural and morphological analyses of the catalysts were carried out by high resolution transmission electron microscopy (HRTEM) using a field emission gun TECNAI G2 F20 microscope (FEI Company, Hillsboro, OR, USA), operated at $200 \mathrm{kV}$. This equipment was also used for undertaking selected area electron diffraction (SAED) and energy dispersive X-ray spectroscopy (EDX). The preparation of the catalysts for the TEM analysis involved a treatment by sonicating the samples in absolute ethanol for several minutes. The suspension obtained was placed on a holey carbon film, which was supported on a copper grid. Finally, the copper grid was dried.

Catalysts were submitted to $\mathrm{N}_{2}$ adsorption at $-196^{\circ} \mathrm{C}$, using a Micromeritics ASAP 2020 apparatus (Norcross, GA, USA). Catalysts were degassed at $150{ }^{\circ} \mathrm{C}$ before the analysis. Total pore volumes were determined, employing the adsorbed volume at a relative pressure of 0.97. A multipoint Brunauer-Emmet-Teller $(\mathrm{BET})$ specific surface area $\left(\mathrm{S}_{\mathrm{BET}}\right)$ was determined through the relative pressure range from 0.05 to 0.25 . The pore size distribution was analyzed using the Barrett-Joyner-Halenda $(\mathrm{BJH})$ method by analyzing the adsorption branch of the $\mathrm{N}_{2}$ adsorption isotherms.

Powder X-ray diffraction (XRD) was employed to know the crystalline phases of the samples. An Enraf Nonius FR590 sealed tube diffractometer (Bruker, Delft, The Netherlands) with a monochromatic $\mathrm{Cu} \mathrm{K} \alpha 1$ source operating at $40 \mathrm{kV}$ and $30 \mathrm{~mA}$ was used.

Temperature programmed reduction (TPR) experiments were conducted using a Micromeritics Autochem 2910 apparatus (Norcross, GA, USA) with a thermal conductivity detector. The gas employed consisted of a mixture of $\mathrm{H}_{2}$ in argon (10\% hydrogen) with a total flow rate of $50 \mathrm{~mL} \mathrm{~min}{ }^{-1}$. 
The temperature range studied was from ambient temperature to $700{ }^{\circ} \mathrm{C}$, and the heating rate was fixed at $10{ }^{\circ} \mathrm{C} \mathrm{min}^{-1}$.

\subsubsection{Catalytic Tests and Analyses}

As mentioned above, after the metal oxide precursors had been prepared, they were reduced in a flow of $\mathrm{H}_{2}\left(30 \mathrm{~mL} \mathrm{~min}^{-1}\right)$ for $3 \mathrm{~h}$ at $400{ }^{\circ} \mathrm{C}$. The catalytic tests were undertaken using hydrothermal conditions, employing a $13 \mathrm{~mL}$ stainless steel autoclave, which was purged with $\mathrm{N}_{2}$ in order to minimize the possible metal oxidation. The autoclave inner walls were covered by a Teflon container (own manufacturing), which fits with the steel walls. The feed consisted of levulinic acid (140 mg) and water $(3.5 \mathrm{~mL})$. The amount of catalyst used was typically $62.5 \mathrm{mg}$. Other experiments with 20.8 and $125 \mathrm{mg}$ were conducted in order to check the influence of the amount of catalyst on the catalytic performance. The autoclave was thoroughly sealed and was then introduced in an oven previously heated at the desired reaction temperature (mainly at $180^{\circ} \mathrm{C}$ ) for the duration of the experiments (typically $2 \mathrm{~h}$ ), and it was then quickly cooled in an ice-bath. Reaction time was considered as the time the autoclave had been introduced in the oven (therefore there was an induction time until the mixture reached the desired temperature, which was considered in the reaction time). The product obtained was recovered by filtration using an appropriate membrane.

For comparison, some selected standard experiments in the presence of hydrogen and stirring were conducted in a Parr autoclave (Moline, IL, USA). The batch reactor had a volume of $100 \mathrm{~mL}$, whereas the stirring speed was fixed in $1200 \mathrm{rpm}$. Previous to the experiment, the batch was filled three times with hydrogen and vented. The pressure hydrogen employed was $3 \mathrm{MPa}$ and the water volume was $40 \mathrm{~mL}$. A total of $1 \mathrm{~g}$ of levulinic acid was used, and the amount of catalyst employed was $62.5 \mathrm{mg}$. After the reaction, the reaction mixture was cooled until room temperature with ice and then filtered, as in the former assays.

\subsection{Analytical Method}

The products obtained were analyzed, as described in Reference [37]. The samples were identified by gas chromatography, using the GC instrument Hewlett Packard 5890 (Palo Alto, California, Estados Unidos), equipped with an Agilent HP-1 column $(30 \mathrm{~m} \times 0.32 \mathrm{~mm} \times 0.25 \mu \mathrm{m})$. The detector employed was a FID detector working at $240{ }^{\circ} \mathrm{C}$, and an injection port, working at $220^{\circ} \mathrm{C}$. The temperature program for a typical run was as follows: (i) $35^{\circ} \mathrm{C}$ isothermal for $6 \mathrm{~min}$, (ii) from 35 to $230^{\circ} \mathrm{C}$ with a heating rate of $20^{\circ} \mathrm{C} \mathrm{min}^{-1}$, and (ii) isothermal at $230{ }^{\circ} \mathrm{C}$ for $26 \mathrm{~min}$. The retention times for the main components GVL and LA were 5.4 and $9.5 \mathrm{~min}$, respectively. The LA conversion was compared against a blank run, undertaken at room temperature and in absence of a catalyst. Experiments with a gas chromatography mass spectrometer (GC-MS 5977A MSD-7890A, Agilent, Santa Clara, CA, USA) were carried out in order to identify the minority reaction products.

\section{Results and Discussion}

\subsection{Characterization Results}

Table 1 shows some characteristics of the nickel oxide precursors and metallic nickel catalysts synthesized. The standard $\mathrm{NiO}$ precursor synthesized by a simple method (NiSTD precursor) presented the lowest surface area $\left(3.4 \mathrm{~m}^{2} \mathrm{~g}^{-1}\right)$. The sample prepared using oxalic acid (NiOXA precursor) showed an increased surface area, which was four times higher than that of the standard Ni. Finally, the sample prepared by the nanocasting route (NiNC precursor) reached the highest surface area, $39 \mathrm{~m}^{2} \mathrm{~g}^{-1}$. 
Table 1. Characteristics of the nickel oxide precursors and final reduced nickel catalysts.

\begin{tabular}{cccccc}
\hline Preparation & Sample & $\begin{array}{c}\mathbf{S}_{\text {BET }} \\
\mathbf{m}^{\mathbf{2}} \mathbf{g}^{\mathbf{- 1}} \mathbf{)}\end{array}$ & $\begin{array}{c}\text { Crystalline } \\
\text { Phases }\end{array}$ & $\begin{array}{c}\text { NiO or Ni Crystallite } \\
\text { Size by XRD }(\mathbf{n m})^{\mathbf{1}}\end{array}$ & $\begin{array}{c}\text { Residual Silicon } \\
\text { Si/Ni at. Ratio } \mathbf{\%}^{\mathbf{2}}\end{array}$ \\
\hline Commercial & $\mathrm{NiCOM}$ & $<1$ & $\mathrm{Ni}$ & 47 & $\sim 0$ \\
\hline \multirow{2}{*}{ Standard } & Precursor & 3.4 & $\mathrm{NiO}$ & 35 & $\sim 0$ \\
& Catalyst NiSTD & 3 & $\mathrm{Ni}$ & 39 & $\sim 0$ \\
\hline \multirow{2}{*}{ Soft template } & Precursor & 15 & $\mathrm{NiO}$ & 26 & $\sim 0$ \\
& Catalyst NiOXA & 7 & $\mathrm{Ni}$ & 34 & $\sim 0$ \\
\hline Ordered, hard & Precursor & 39 & $\mathrm{NiO}$ & 19 & $\sim 0.3$ \\
Template & Catalyst NiNC & 13 & $\mathrm{Ni}$ & 31 & $\sim 0.4$ \\
\hline
\end{tabular}

${ }^{1}$ Mean $\mathrm{NiO}$ crystallite size has been determined from the XRD patterns, applying the Scherrer equation; ${ }^{2}$ amount of silicon detected by energy dispersive $\mathrm{X}$-ray spectroscopy (EDX) analyses, expressed as $\mathrm{Si} / \mathrm{Ni}$ at. ratio.

The XRD patterns of all the nickel oxide precursors (Figure 1) show that cubic $\mathrm{NiO}$ is the only crystalline phase detected (NiO, JCPDS: 47-1049). However, an appreciable difference can be observed in both the surface areas and the crystallite sizes (Table 1). The highest surface area $\left(39 \mathrm{~m}^{2} \mathrm{~g}^{-1}\right)$ and the lowest $\mathrm{NiO}$ crystallite size $(19 \mathrm{~nm})$ are then observed for the nanocasting sample. Conversely, the standard $\mathrm{NiO}$ presents the lowest surface area $\left(3.4 \mathrm{~m}^{2} \mathrm{~g}^{-1}\right)$ and the highest crystallite size $(35 \mathrm{~nm})$. As expected, an inverse relationship between surface area and $\mathrm{NiO}$ crystalline size is observed.
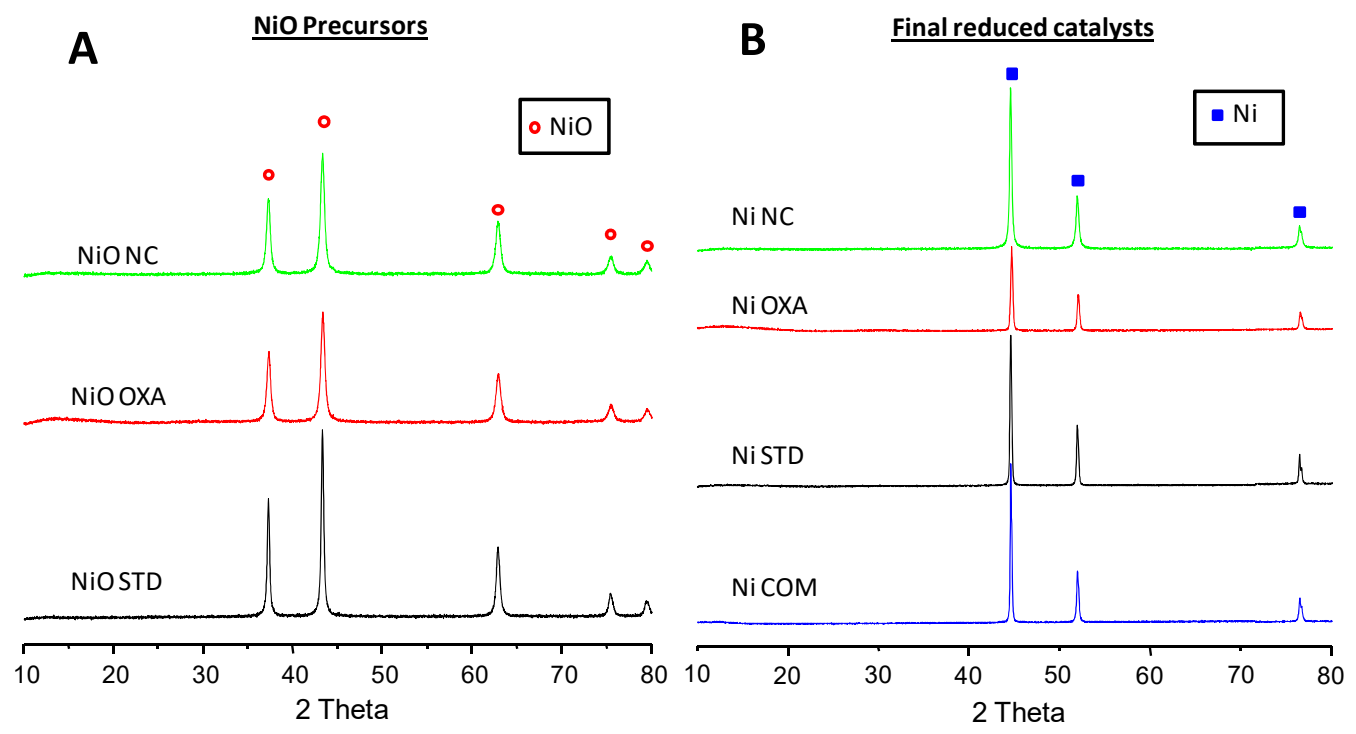

Figure 1. XRD patterns of $\mathrm{NiO}$ precursors $(\mathbf{A})$ and final reduced Ni catalysts $(\mathbf{B})$.

Figure 1, also shows the XRD of the final reduced catalysts. It can be seen that the only crystalline phase present in these reduced catalysts is metallic Ni (JCPDS: 01-1260), although the width of the peaks slightly varies. As it has been observed for the precursors, the lowest surface area $\left(<1 \mathrm{~m}^{2} \mathrm{~g}^{-1}\right)$ and the highest mean Ni crystallite size $(\mathrm{ca} .50 \mathrm{~nm})$ correspond to the commercial catalyst. The surface area follows an inverse trend to that of the crystallite size. The surface area varies according to: NiCOM $<\mathrm{NiSTD}<\mathrm{NiOXA}<\mathrm{NiNC}$, which is the same trend observed for the precursors. It must be noted that the surface areas of the precursors are in all cases higher than those of the reduced final catalysts. The additional heat treatment in hydrogen flow at $400{ }^{\circ} \mathrm{C}$, with the consequent modification of the crystalline structure, are likely to be the responsible for this surface area drop.

Low angle XRD from 2 theta $=1^{\circ}$ was examined for both the $\mathrm{NiO}$ precursors, synthesized by a nanocasting route and the reduced final NiNC catalyst (not shown here). In the case of the final NiNC catalyst, no maxima associated to an ordered mesoporous structure were observed, whereas in the case of the precursor, the presence of low intensity bands at ca. 1.2 and $1.7^{\circ}$ cannot be ruled out. 
The precursor and the catalyst with the highest surface area are those prepared by a nanocasting route. This method allows high surface area materials with a high extent of order, and its shape is determined by the pores of the siliceous hard template used in the preparation method. In order to corroborate the appropriate preparation of this material, a TEM study was then undertaken. The $\mathrm{NiO}$ precursor shows the typical image of a nanocasted structure, with very well-defined rods and pores. Moreover, the use of KIT-6 allows the rods formed to be interconnected, making possible a compact structure (Figure 2). The length of the rods is quite homogeneous with a mean width of ca. $7 \mathrm{~nm}$, whereas the free space between the rods is smaller than $1 \mathrm{~nm}$ wide (intraparticle porosity). Therefore, we can conclude that a reasonably good ordered replica of siliceous KIT-6 has been obtained.

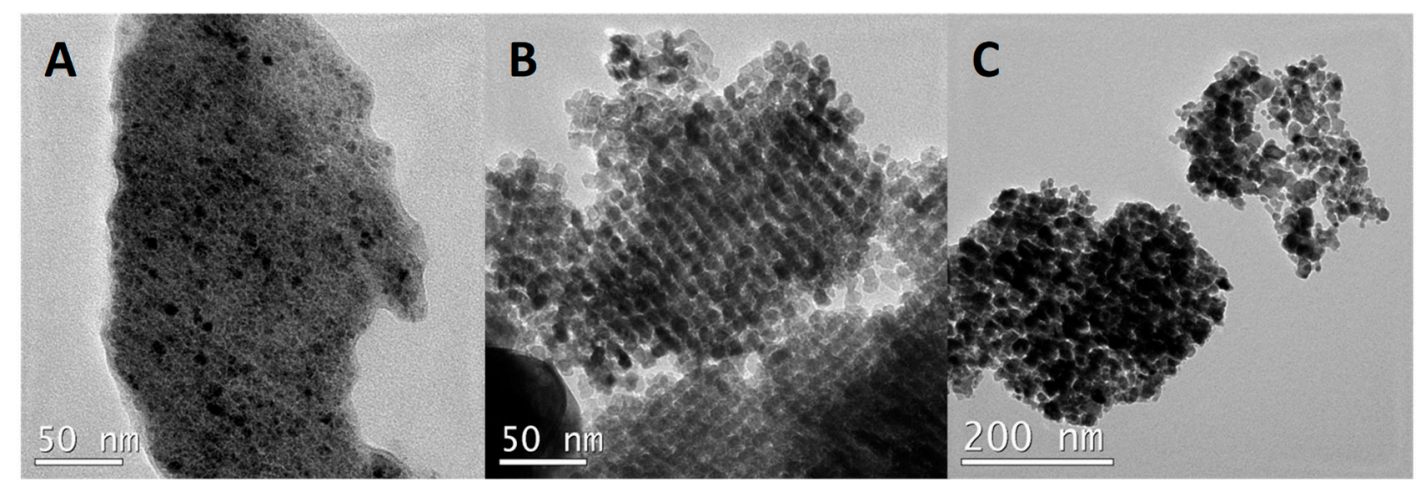

Figure 2. Representative transmission electron microscopy (TEM) images of different nickel containing samples: (A) NiCOM, (B) $\mathrm{NiO}$ precursor of $\mathrm{NiNC}$, and (C) NiNC.

Unfortunately, the reduction of the $\mathrm{NiO}$ prepared by nanocasting does not allow us to maintain the ordered structure, although the final catalyst keeps important porosity. NiNC presents a morphology consisting of agglomerations of nanoparticles (NPs). The agglomerations present a variable size; in fact, after a detailed study of the sample, we have observed relatively small agglomerations with diameters of $50 \mathrm{~nm}$ and some others exceeding $400 \mathrm{~nm}$. The size of the nanoparticles conforming the agglomerations is mainly in the 6 to $20 \mathrm{~nm}$ range. Whilst intraparticle porosity completely disappears, some interparticle mesoporosity is preserved after $\mathrm{H}_{2}$ reduction.

For comparison, the commercial metallic nickel (NiCOM) has been also studied by TEM. The morphology drastically changes compared to the former samples. Thus, large particles with sizes between 100 and $300 \mathrm{~nm}$ are predominant in this sample. Apparently, no porosity has been observed inside these particles. Interestingly, the image of the Ni particles detects zones with different contrast, although a detailed analysis by selected area electron diffraction (SAED) shows, for any zone of the catalyst studied, the unique presence of metallic $\mathrm{Ni}$.

Figure 3 shows the SAED patterns for both the precursor and the NiNC catalysts. The precursor shows six defined diffraction rings (inset of Figure $3 \mathrm{~A}$ ) that, in agreement with the $\mathrm{NiO}$ phase (JCPDS: 47-1049) and the Bragg diffraction law, can be indexed to a face-centered cubic phase of NiO. The main distances detected are 2.41, 2.09, 1.48, and $1.26 \AA$, which correspond to the (111), (200), (220), and (311) planes of cubic NiO. No other nickel containing phase has been detected along the catalyst.

In the case of the final NiNC catalyst, the diffraction rings show the only presence of metallic $\mathrm{Ni}$, indicating that the hydrogen treatment submitted to the precursor has completely reduced the nickel oxide into metallic Ni. The main distances observed are 2.04, 1.78, 1.27, and $1.10 \AA$, which correspond to the (111), (200), (220), and (311) planes of cubic Ni. In this sample, no other Ni-phase has been detected. This is in agreement with the XRD observations. 

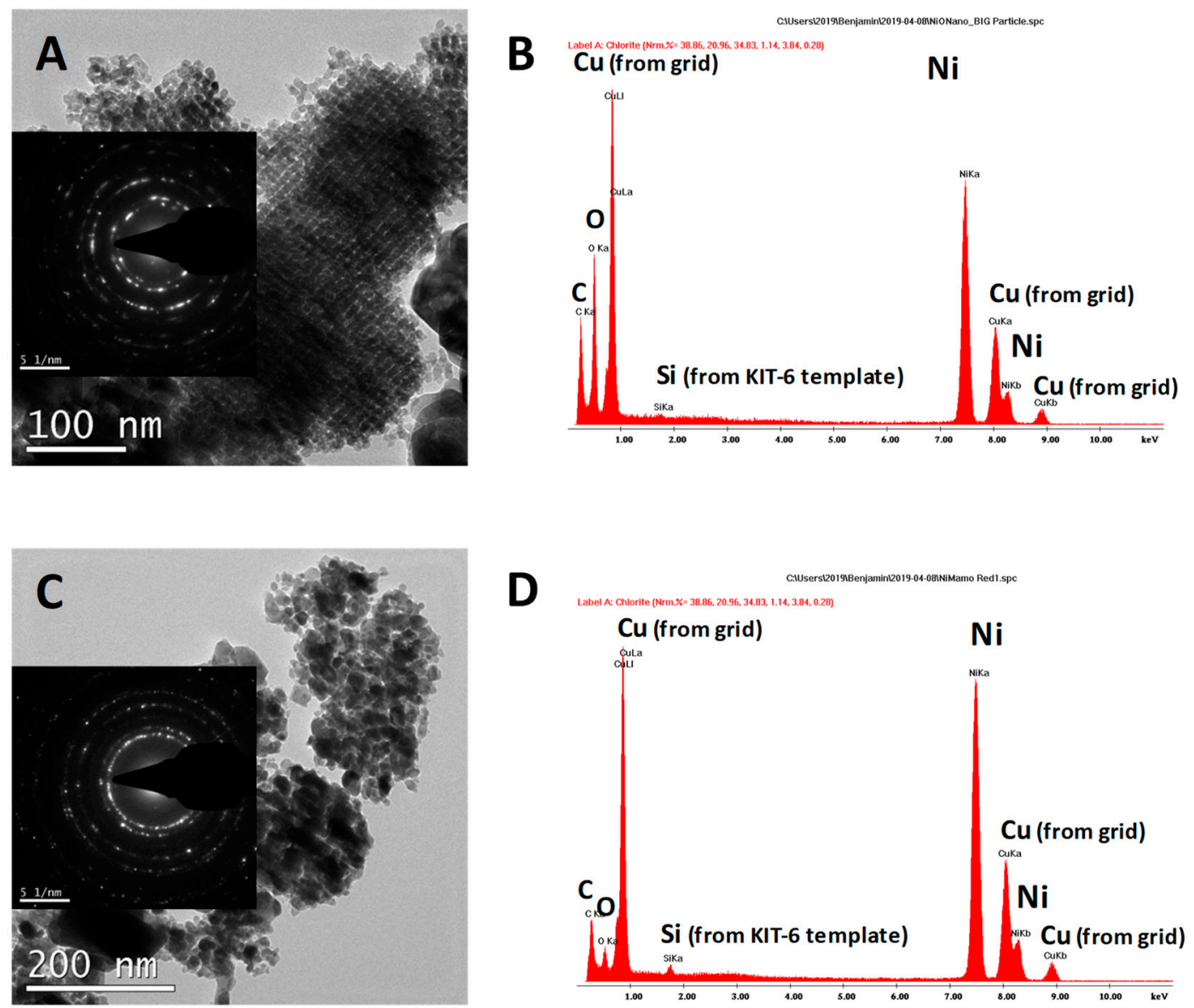

Figure 3. Representative TEM images with the corresponding selected area electron diffraction (SAED) patterns (inset) for (A) $\mathrm{NiO}$ precursor of $\mathrm{NiNC}$ and (C) NiNC catalyst. EDX analyses of (B) $\mathrm{NiO}$ precursor of NiNC and (D) NiNC catalyst.

The nanocasting route for preparing metal oxides involves the elimination of the hard templates (in our case silica). Therefore, it is important to control the extent of the silica removal in order to check the quality of the synthesis. The chemical composition of the specimens was then undertaken by EDX analysis, using a transmission microscope. Thus, the EDX analyses of both precursor and NiNC catalysts are shown in Figure 3B,D. Positively, the amount of silicon observed in both cases is very low ( $\mathrm{Si} / \mathrm{Ni}$ at. ratio lower than $0.5 \%$ ). In the EDX analyses, other elements, such as $\mathrm{C}$ and $\mathrm{Cu}$, have been detected, due to the use as a sample holder of holey-carbon film supported on copper grids. Oxygen has been also detected, showing in the $\mathrm{NiO}$ precursor a higher relative amount than in the final catalyst, in agreement with the different nickel-containing species present in each sample. Moreover, in these samples, the presence of sodium from the sodium hydroxide used to remove silica can be possible if the washing procedure is not thoroughly undertaken. Interestingly, in our case, EDX analysis does not reveal the existence of sodium and, if present, is below the detection limit of the technique.

In order to know the surface area as well as the type of porosity for both the precursor and the NiNC catalyst, the adsorption-desorption isotherms and the pore distribution are shown in Figure 4. The NiO precursor synthesized by a nanocasting method presents a relatively high surface area, $39 \mathrm{~m}^{2} \mathrm{~g}^{-1}$, which is significantly decreased for the reduced sample, $13 \mathrm{~m}^{2} \mathrm{~g}^{-1}$. The nitrogen adsorption isotherms for the Ni-based catalysts prepared by the nanocasting method are presented in Figure 4A. Both isotherms are type IV with $\mathrm{H} 1$ type hysteresis, which are typical of mesoporous materials. It can be clearly observed that the $\mathrm{NiO}$ precursor accounts for both a more pronounced hysteresis and a higher $\mathrm{N}_{2}$ adsorption capacity at high relative pressures, again showing that the mesopore structure of the intraparticle porosity of the $\mathrm{NiO}$ partially collapses during the reduction step. The $\mathrm{BJH}$ approach 
applied to the adsorption branch of the isotherms is plotted in Figure 4B. For the $\mathrm{NiO}$ precursor and the NiNC catalyst, three different ranges of pores can be found, with mean pore sizes about $4 \mathrm{~nm}, 23 \mathrm{~nm}$, and $10 \mathrm{~nm}$, respectively. In a perfect KIT- 6 replication process, the mesochannels of KIT-6 and their connecting microchannels are filled with the metal oxide, and then the siliceous walls between them are dissolved and eliminated, leading to the formation of pores of ca. $4 \mathrm{~nm}$. However, if the partial replication process is not fully achieved, the simultaneous occupation of the KIT-6 microchannels is not accomplished and pores centered at about $15-20 \mathrm{~nm}$ are also obtained, which is consistent with observations in the current study. Moreover, it must be noted that for the $\mathrm{NiO}$ material there is some evidence of the formation of macropores (pores higher than $50 \mathrm{~nm}$ ), likely proceeding from large interstitial pores generated between the $\mathrm{NiO}$ nanocast particles. The presence of this macroporosity could be positive, since it could improve the diffusion of large organic molecules to the active sites. A different pore size distribution is clearly observed after the reduction process. Whilst both broad mesopores at about 10-20 $\mathrm{nm}$ and macropores are significantly preserved, the narrowest mesopores observed for the $\mathrm{NiO}$ precursor at about $4 \mathrm{~nm}$ almost disappear. This evolution of the catalyst porosity after $\mathrm{H}_{2}$ reduction can be ascribed to the sintering due to the reduction treatment at high temperatures, as well as the modification of the structure due to the O-loss from the $\mathrm{NiO}$ precursor to the final Ni particles.
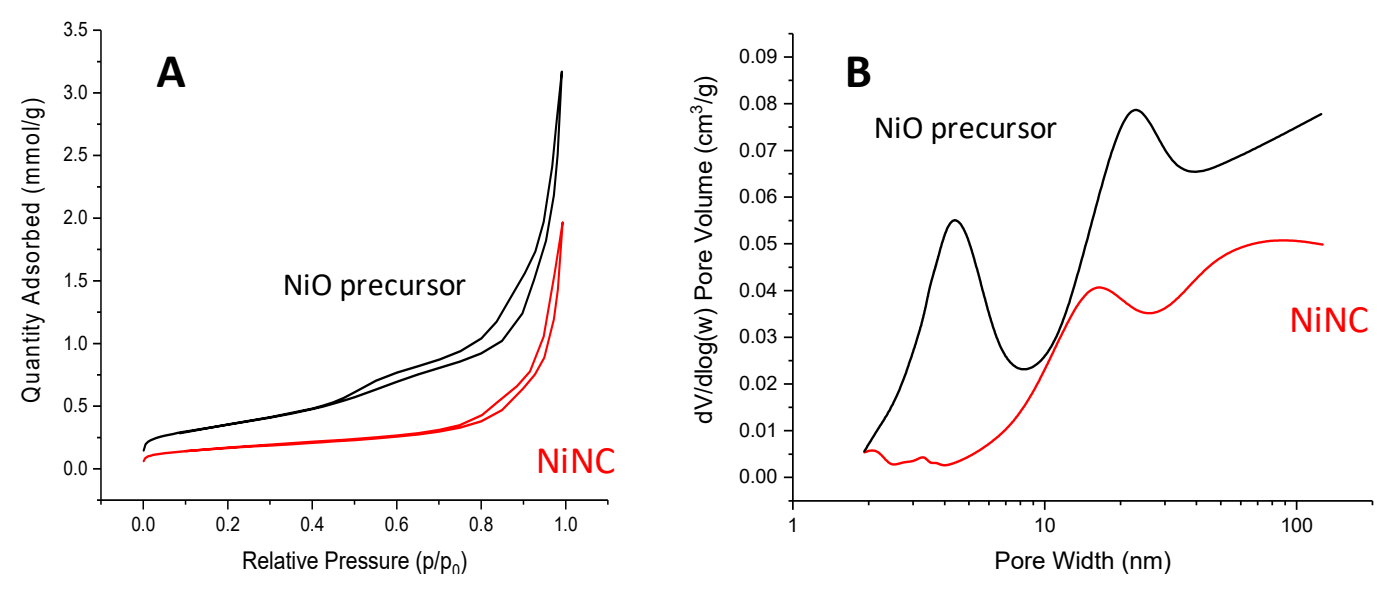

Figure 4. Adsorption-desorption isotherms (A) and pore distribution (B) of both the $\mathrm{NiO}$ precursor and the NiNC catalyst.

Therefore, a reasonable NiO replica of the siliceous KIT-6 has been obtained by the nanocasting route. Unfortunately, the reduction with hydrogen of $\mathrm{NiO}$ leads to the collapse of the pores at ca. $4 \mathrm{~nm}$ and a consequent drop in the surface area.

Previously to undertaking the reaction, the nickel oxides were reduced at $400{ }^{\circ} \mathrm{C}$ in the hydrogen flow. We used that temperature to ensure that all nickel oxides were reduced into metallic nickel. The temperature programmed reduction experiments show that, for all nickel oxide precursors, total reduction takes place at temperatures below $400{ }^{\circ} \mathrm{C}$ (Figure 5).

For all precursors, a main peak with a shoulder at higher temperatures is observed, which has been associated with larger $\mathrm{NiO}$ particles [38,39] due to certain heterogeneity in the samples. It must be noted that the hydrogen consumption in the TPR experiments adjusts with the $\mathrm{NiO} \rightarrow \mathrm{Ni}$ transition with a low error $( \pm 6 \%)$. 


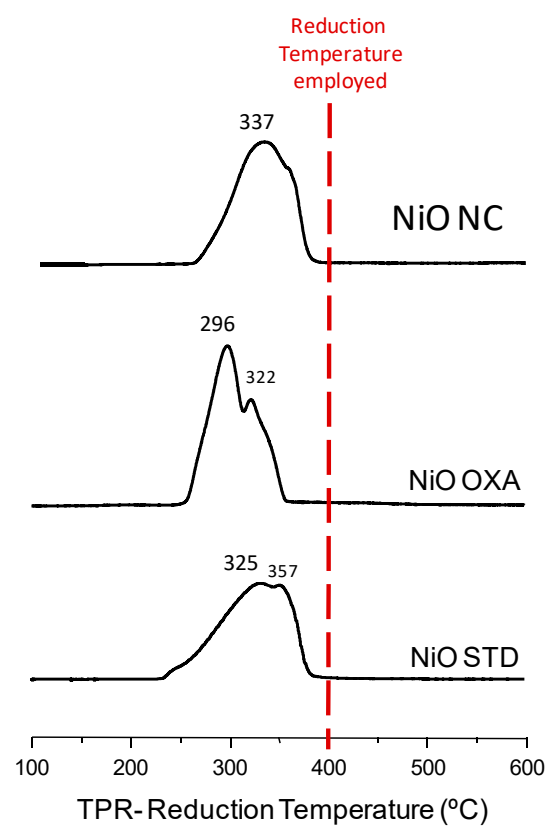

Figure 5. Temperature programmed reduction of nickel oxide precursors prepared by different preparation procedures.

\subsection{Catalytic Results}

In this work, we tried to take advantage of the properties of water at high temperature, since, this way, water can be the source for hydrogen, which is needed for the hydrogenation reaction of LA into GVL [37]. The typical reactions undertaken in this work are conducted using a closed autoclave with a teflon container at a reaction temperature of $180{ }^{\circ} \mathrm{C}$. GVL is observed in most of the experiments conducted in the presence of catalysts. Conversely, the blank experiment in the absence of the catalyst gives a null conversion. In order to ensure the absence of catalytic potential of the bare reactor, experiments at higher temperatures were undertaken. Interestingly, at $220^{\circ} \mathrm{C}$, the LA conversion obtained without a catalyst is negligible.

The first experiments were undertaken at $180^{\circ} \mathrm{C}$ with the differently prepared metallic Ni catalysts. Figure 6 shows the yield to GVL obtained by the different nickel catalysts. Commercial Ni showed a yield to GVL very low (ca. $0.2 \%$ ). Significantly, the use of the other metallic nickel-based catalysts meant a drastic improvement. Using the standard nickel (NiSTD), a yield to GVL of $18 \%$ was then achieved. Similarly, the Ni catalyst synthesized from the $\mathrm{NiO}$ prepared with oxalic acid (NiOXA) achieved a yield of $16 \%$. Finally, the $\mathrm{Ni}$ derived from the $\mathrm{NiO}$ prepared by a nanocasting route was the most efficient catalyst with a yield to GVL of $34 \%$. It is interesting to note that the selectivity to GVL obtained by all the nickel catalysts exceeds $98 \%$ (Table 2). Apart from GVL traces of different by-products (formic acid, acetic acid, isobutyric acid, pentanoic acid, 4-hydroxy-2-butanone, and heavy oxygenated products) are observed.

The higher reactivity of the NiNC catalyst can be due to the higher surface area of this sample, this way allowing a higher number of active sites. However, if we consider the catalytic activity per surface area of the catalyst, we can observe that the sample NiSTD is the one with the highest value $\left(5.6 \times 10^{-4} \mathrm{~mol}_{\mathrm{GVL}} \mathrm{m}^{-2} \mathrm{~h}^{-1}\right)$, whereas NiNC presents a lower value $\left(2.52 \times 10^{-4} \mathrm{~mol}_{\mathrm{GVL}} \mathrm{m}^{-2} \mathrm{~h}^{-1}\right.$, respectively). The reason that explains this different areal rate is not straightforward to justify, although maybe a part of the lower areal rate of NiNC can be related to the presence of silicon on its surface, this way hindering the nickel-LA interaction. We have not given data of the areal rate obtained with the commercial metallic nickel because this catalyst presents a surface area which is lower than $1 \mathrm{~m}^{2} \mathrm{~g}^{-1}$, and then the error involved for determining the areal rate would be very high. 

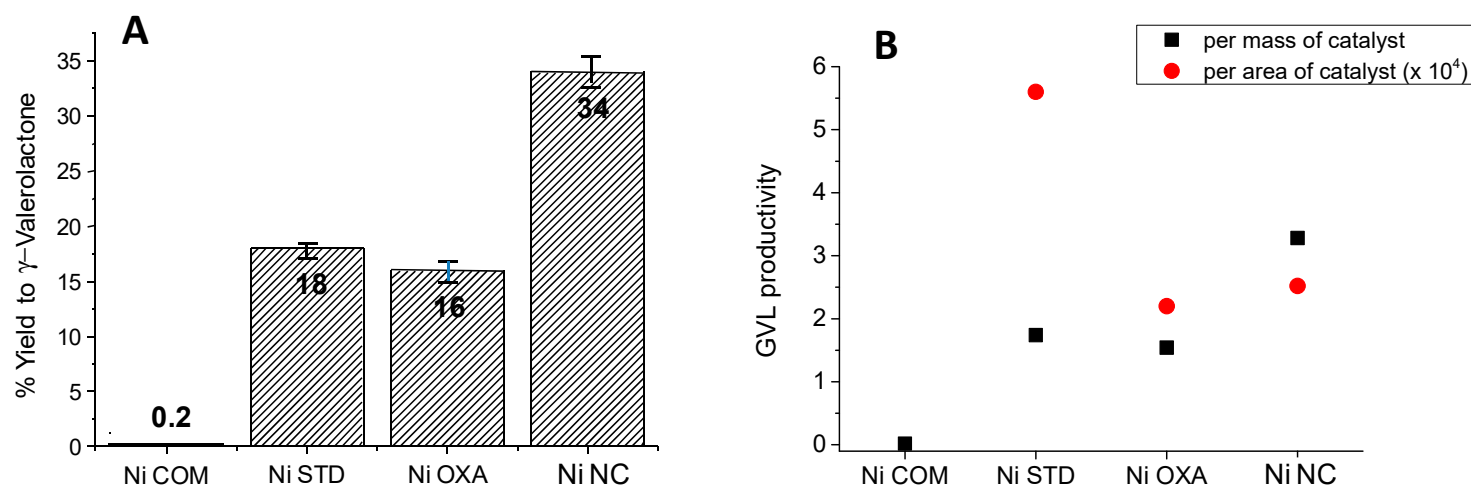

Figure 6. Catalytic results of the levulinic acid transformation into $\gamma$-valerolactone on different $\mathrm{Ni}$ catalysts: (A) Yield to $\gamma$-valerolactone, (B) productivity to $\gamma$-valerolactone per mass of catalyst ( $\mathbf{\square}$ ) or per surface area (๑). Notes: Reaction temperature $=180^{\circ} \mathrm{C}$, reaction time $=2 \mathrm{~h}, 62.5 \mathrm{mg}$ of catalyst and remaining reaction conditions in the Materials and Method section. Productivity per mass of catalyst expressed as $\mathrm{mol}_{\mathrm{GVL}} \mathrm{Kg}_{\mathrm{cat}}{ }^{-1} \mathrm{~h}^{-1}$. Productivity per area of catalyst expressed as $10^{-4} \mathrm{~mol}_{\mathrm{GVL}} \mathrm{m}^{-2} \mathrm{~h}^{-1}$.

Table 2. Levulinic acid (LA) conversion, yield to GVL, and selectivity to GVL obtained at $180{ }^{\circ} \mathrm{C}$ using nickel catalysts. Comparison between the hydrothermal conditions mainly used in this work and standard conditions with hydrogen pressure and stirring.

\begin{tabular}{ccccccc}
\hline \multirow{2}{*}{ Sample } & \multicolumn{3}{c}{ Hydrothermal Conditions $^{\mathbf{1}}$} & \multicolumn{3}{c}{ Standard Conditions $^{\mathbf{2}}$} \\
\cline { 2 - 7 } & Conversion & Yield & Selectivity & Conversion & Yield & Selectivity \\
\hline NiCOM & 0.2 & 0.2 & 100 & 7.9 & 7.4 & 95.2 \\
NiSTD & 17.9 & 17.7 & 98.8 & 79.2 & 77.2 & 97.5 \\
NiOXA & 16.7 & 16.4 & 98.2 & 75.7 & 74.3 & 98.2 \\
NiNC & 35.0 & 34.3 & 98.0 & 99.4 & 96.8 & 97.4 \\
\hline
\end{tabular}

${ }^{1}$ Reaction time $=2 \mathrm{~h}, 62.5 \mathrm{mg}$ of catalyst, $0.14 \mathrm{mg}$ of LA, $3.5 \mathrm{~mL}$ water; ${ }^{2}$ reaction time $=2 \mathrm{~h}, 62.5 \mathrm{mg}$ of catalyst, $1 \mathrm{~g}$ of LA, $1200 \mathrm{rpm}, \mathrm{H}_{2}$ pressure $=3 \mathrm{MPa}$.

The catalytic performance of the $\mathrm{NiO}$ precursor in conventional reaction conditions was also explored. It has been widely reported that metals, such as $\mathrm{Ni}$, are remarkably more efficient than their corresponding metal oxides. Accordingly, the experiment undertaken with the $\mathrm{NiO}$ precursor of NiNC demonstrates very low capacity for GVL production. In fact, not even traces of GVL have been observed in this case.

For a comparative purpose, these catalysts were tested in standard conditions in the presence of hydrogen $(3 \mathrm{MPa})$, stirring $(1200 \mathrm{rpm})$ at the same temperature of $180^{\circ} \mathrm{C}$. As the reaction conditions are not the same, see the Materials and Methods section, and an exact comparison is not possible. However, we have seen the same trend, using the hydrothermal conditions, as the nickel catalyst prepared by the nanocasting route was the most active and the commercial catalyst the least active. The selectivity observed in all cases was very high (over 95\%). It is interesting to note that a yield of GVL higher than ca. $97 \%$ was obtained in the NiNC catalyst.

\section{Discussion}

Once we knew that metallic nickel can activate levulinic acid at relatively low temperatures, we also wanted to determine the effect of the reaction conditions on the catalytic performance. Firstly, the influence of the reaction temperature on the LA conversion and on the productivity to GVL has been studied on NiCOM, NiSTDm and NiNC catalysts (Figure 7). As expected, the GVL formation increases with the reaction temperature in the temperature range studied $\left(150-220^{\circ} \mathrm{C}\right)$. Commercial nickel hardly forms GVL even at the highest temperature tested, whereas both NiSTD and NiNC present a similar trend, but with the catalyst derived from the nanocasting route presenting higher GVL formation. 
A

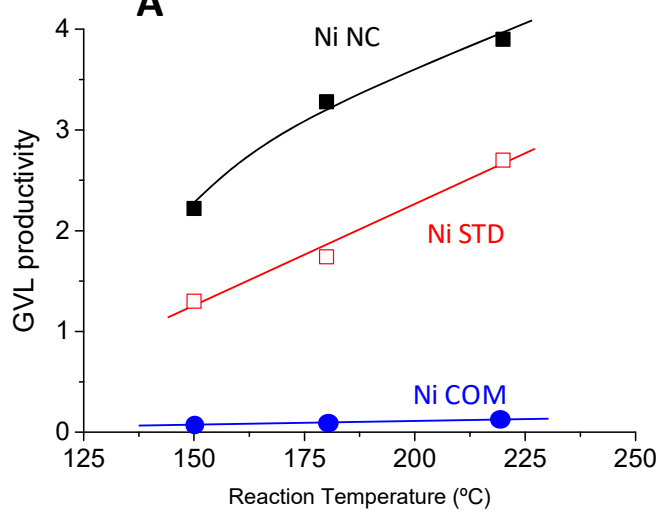

B

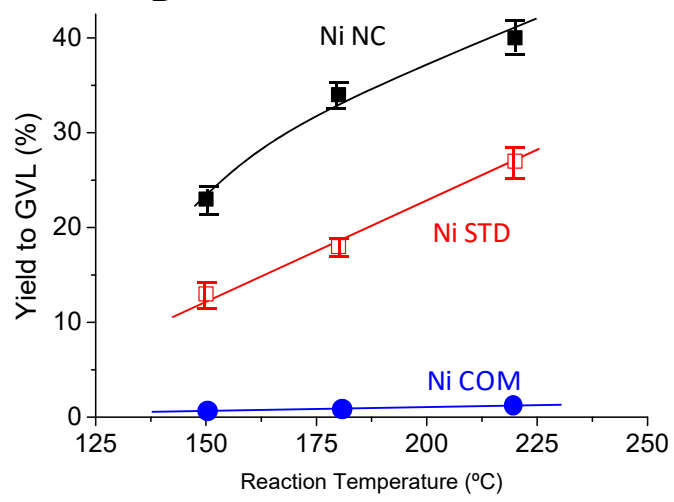

Figure 7. Effect of the reaction temperature on the catalytic performance of NiNC ( $\mathbf{\square}), \operatorname{NiSTD}(\square)$, and NiCOM (๑): (A) Productivity to $\gamma$-valerolactone per mass of catalyst, (B) yield to $\gamma$-valerolactone, Notes: Reaction temperature $=150-220^{\circ} \mathrm{C}$, reaction time $=2 \mathrm{~h}, 62.5 \mathrm{mg}$ of catalyst, remaining conditions in the Materials and Method section. Productivity per mass of catalyst expressed as $\operatorname{mol}_{\mathrm{GVL}} \mathrm{Kg}_{\mathrm{cat}}{ }^{-1} \mathrm{~h}^{-1}$.

The influence of the reaction time on the catalytic performance has been also studied using the NiNC catalyst (Figure 8A). It can be observed that the yield to GVL increases when the reaction time increases. After $30 \mathrm{~min}$ in the furnace, the amount of GVL observed is not high (yield ca. $2 \%$ ), whereas after $60 \mathrm{~min}$ and $120 \mathrm{~min}$ the yield increased to 17 and 34\%, respectively. Further increase in the reaction time has led to an increase of the yield to GVL, although not proportional to the reaction time. If we consider the productivity (per unit time and per mass of catalyst) a maximum is observed at 60 and $120 \mathrm{~min}$. The reason after the low productivity observed at $30 \mathrm{~min}$ can be due to the characteristics of the catalytic experiments carried out. In our tests, we place the autoclave into a furnace previously heated at $180^{\circ} \mathrm{C}$. For short reaction times, as in our case at $30 \mathrm{~min}$, it was then possible that the temperature of the reaction mixture only reached the desired reaction temperature $\left(180^{\circ} \mathrm{C}\right)$ for a segment of that period.
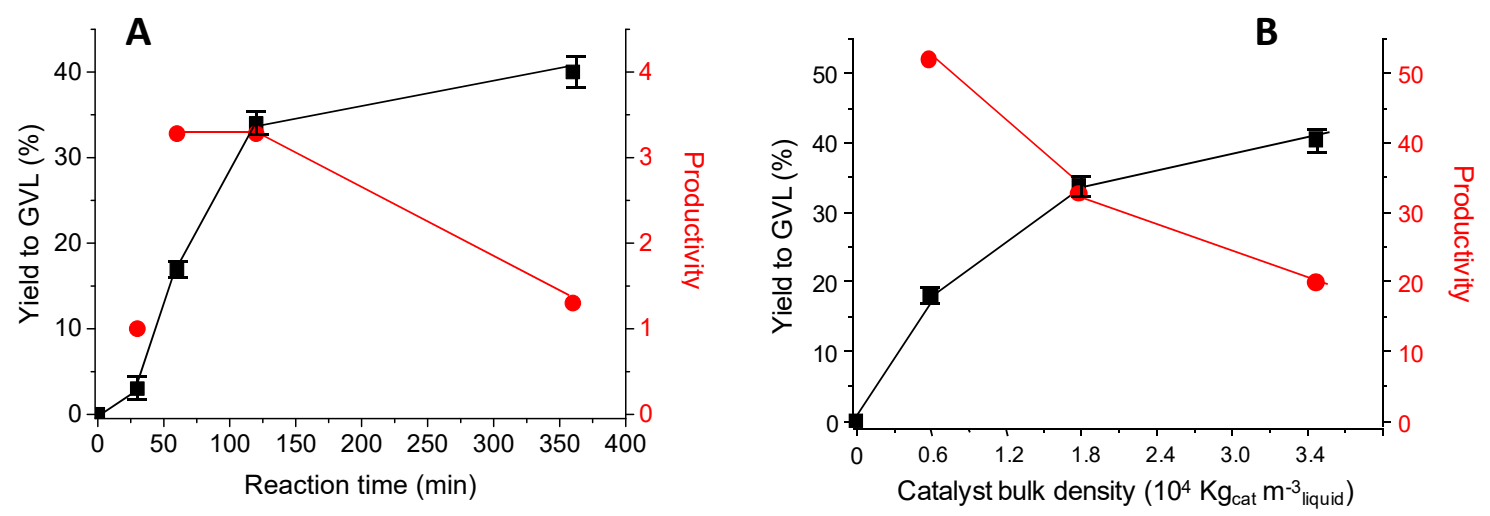

Figure 8. Influence of the reaction time (A) and the catalyst bulk density (B) on the yield to $\gamma$-valerolactone ( $\square$ ) and on the productivity to $\gamma$-valerolactone per mass of catalyst (๑) using NiNC catalyst. Notes: Reaction temperature $=180^{\circ} \mathrm{C}$. (A) Catalyst weight $=62.5 \mathrm{mg}$ and different reaction times. (B) Reaction time $=2 \mathrm{~h}$ and different catalyst bulk densities. Productivity per mass of catalyst expressed as mol $_{\mathrm{GVL}} \mathrm{Kg}_{\mathrm{cat}}{ }^{-1} \mathrm{~h}^{-1}$.

The effect of the amount of catalysts on the GVL formation has also been studied (Figure 8B). As expected, the higher the catalyst weight the higher the yield to GVL. However, the increase in the yield slows down when increasing the catalyst loading. Therefore, the productivity (per unit time and per mass of catalyst) decreases when the catalyst weight increases. 
In this article, it has been observed that there is no need to use noble metals in order to efficiently obtain GVL from LA under green and mild conditions. Moreover, the reaction method here employed is extremely easy. The results obtained indicate that metalllic $\mathrm{Ni}$ is highly active in the LA transformation into GVL. However, the preparation method of the Ni-based catalyst is of outstanding importance. Using the same reaction conditions, a commercial $\mathrm{Ni}$ then presents a GVL production of $0.019 \mathrm{~mol}_{\mathrm{GVL}} \mathrm{Kg}_{\mathrm{cat}}{ }^{-1} \mathrm{~h}^{-1}$, whereas $\mathrm{Ni}$ derived from nanocasted $\mathrm{NiO}$ reaches a value which is two orders of magnitude higher $\left(3.28 \mathrm{~mol}_{\mathrm{GVL}} \mathrm{Kg}_{\mathrm{cat}}{ }^{-1} \mathrm{~h}^{-1}\right)$. The higher productivity of NiNC could be related to its higher surface area and lower crystallite size, although the presence of silica on the surface as a result of the preparation method could have a negative impact. The role of the mesoporous structure cannot be elucidated, but it is clear that this approach involves an important catalytic improvement.

In the reaction conditions employed in this article, the presence of the catalyst is essential as the lack of catalyst (mere contact with the Teflon container) does not lead to the LA transformation, even at $220^{\circ} \mathrm{C}$, which is $40^{\circ} \mathrm{C}$ higher than the temperature employed in the present study.

The characterization undertaken shows that the nickel catalysts only present metallic $\mathrm{Ni}$, whereas no oxidized $\mathrm{NiO}$ is observed. TPR experiments corroborate that the reduction conditions employed are appropriate. The crystalline structure of the catalysts used in the reaction do not experience important differences compared to the unused catalysts, although some nickel oxide has been formed. Moreover, the estimated mean crystallite size hardly varies. A close look at the XRD pattern of the used NiNC catalyst shows that apart from the main peaks corresponding to metallic nickel and some low intense peaks that could be assigned to oxidized $\mathrm{NiO}$ are present.

One of the main advantages of the use of supported nickel catalysts is their high reactivity, whereas one of the main drawbacks is associated with the lack of stability. The use of $\mathrm{Ni}-\mathrm{MoO}_{\mathrm{x}} / \mathrm{C}$ has been reported to lead to turnover frequencies similar to those obtained using catalysts with ruthenium [26]. Simple Ni/alumina catalysts achieved GVL yields over $90 \%$, although, unfortunately, it was observed that the GVL formation importantly decreased after being reutilized [27]. Similarly, using Ni/MgO catalysts, high and unstable performance was reported [29]. Conversely, simple $\mathrm{Ni} / \mathrm{SiO}_{2}$ catalysts showed a highly stable GVL production after $25 \mathrm{~h}$ of the experiment [28]. The use of dioxane as a solvent also had an important impact in the reusability of the catalysts [30]. Thus, the catalysts showed a stable activity after being used four times, in spite of the fact that nickel had partly oxidized into nickel oxide. Jiang et al. [40] observed that metallic nickel supported on $\mathrm{MgO} / \mathrm{Al}_{2} \mathrm{O}_{3}$ was highly active at $160{ }^{\circ} \mathrm{C}$, achieving GVL yields over $99.5 \%$. This enhanced catalytic performance was related to the high dispersion of the nickel particles on the $\mathrm{MgO} / \mathrm{Al}_{2} \mathrm{O}_{3}$ surface. These tiny metallic nickel particles were tightly interacting with the support, likely preventing leaching and allowing reutilization. In fact, no loss of activity for at least four uses was observed.

The stability of the NiNC catalyst of the present article was also studied. In order to check the possible leaching in the reaction media, once the reaction finished, the catalyst was filtered. The liquid recovered was then submitted again to the standard reaction conditions $\left(2 \mathrm{~h}\right.$ at $\left.180^{\circ} \mathrm{C}\right)$ in the absence of the catalyst. After that time, it was observed that neither the LA conversion (35\%) nor the yield to GVL 34\%) increased compared to the initial test. In another set of experiments, the NiNC catalyst was reutilized in the reaction three times, but before its use the catalyst was pre-treated in hydrogen. In this case, it was observed that the catalyst did not deactivate as in the used catalyst and the activity obtained corresponded to the amount of catalysts employed, this suggesting that the active nickel sites fully recover its reactivity after reduction. Finally, if NiNC was re-used in the absence of pre-reduction, a decrease in the GVL yield was slight in the first three cycles, from $34 \%$ (first run) to $26 \%$ (third run), and then more drastic ( $10 \%$ in the fourth cycle). This fall can be ascribed to leaching of the active nickel in the reaction media and especially to the lack of hydrogen, due to the oxidation of metallic nickel. These data lead us to conclude that an industrial application using this system is difficult if the regeneration of the sample is not carried out in a simple manner. 
In the future, it would be very interesting to carry out a detailed mechanistic study on the GVL formation from LA using the easy reaction conditions employed in the present work. These metallic nickel catalysts, especially those prepared by a nanocasting route, have shown bifunctionality as they can activate water (as the source for hydrogen) and can also undertake the further hydrogenation step (Figure 9). Conversely to metallic nickel, any nickel oxide tested has shown to be incapable to transform levulinic acid into $\gamma$-valerolactone, indicating that nickel oxide cannot selectively activate levulinic acid in these reaction conditions.
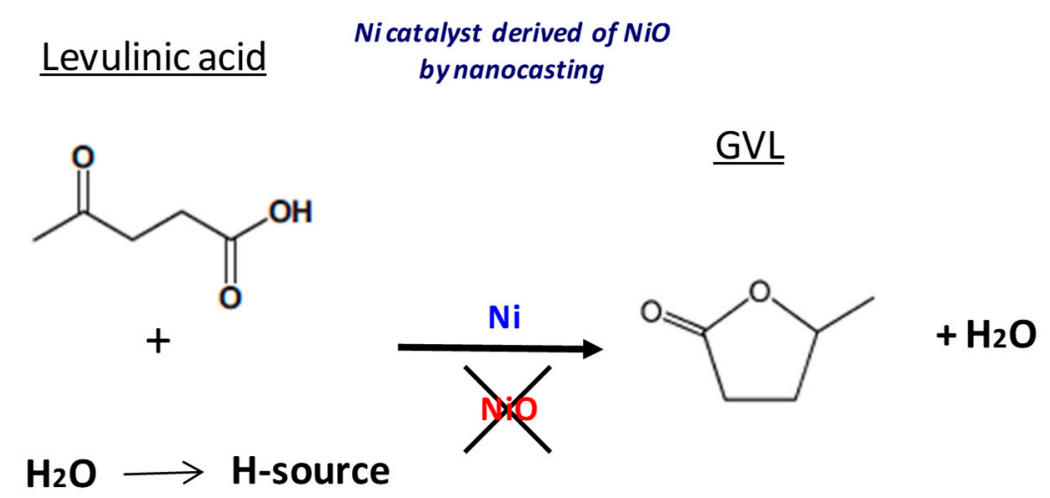

Figure 9. Scheme showing a summary of the experiments carried out in this work.

As mentioned above, levulinic acid transformation into GVL takes place by hydrogenation. The source for hydrogen atoms is molecular $\mathrm{H}_{2}$ in-situ formed. In several experiments, we have extracted the gas from the batch, and we have corroborated the $\mathrm{H}_{2}$ formation. Due to the reaction conditions employed, we have not been able to carry out a precise quantification of the amount of hydrogen formed, but we ensure that this has taken place as we have analyzed the gases after reaction.

Water splitting to obtain hydrogen is easy even at low temperatures, employing a set of metals. By throwing selected metals in water, for example $\mathrm{Mg}$, hydrogen can be directly obtained. However, this is not a catalytic process but the result of the oxidation of the metal to the corresponding oxide or hydroxide with the consequent water splitting and hydrogen formation. Unfortunately, most of metals in the earth are not in the metallic form but as oxides or salts, and then the reduction to the metallic form is not energetically favored. Metallic nickel sites are not only the active sites for the LA to GVL production, but also present the capacity for hydrogen production from water. In fact, nickel has been shown as highly active for water-to-hydrogen conversion via electro-oxidation [41,42]. The origin of the hydrogen proceeds from the water splitting as nickel metal plus water leads to the formation of metal oxide plus hydrogen $\left(\mathrm{Ni}+\mathrm{H}_{2} \mathrm{O} \rightarrow \mathrm{NiO}+\mathrm{H}_{2}\right)$. Nickel the exerts both catalysts for the AL to GVL transformation and also as a source of hydrogen through its oxidation.

The hydrothermal method is a very straightforward reaction method and involves mixing the different participants in the reaction as water works at temperatures higher than that of its boiling point at ambient pressure. In these conditions, the vapor pressure of water increases, this way increasing the kinetic energy of the molecules and the rates of the possible reactions. Therefore, in these conditions there is a rather continuous contact between the reaction media and the catalyst. In fact, our experiments have shown to be highly reproducible. Unfortunately, there are possible mass transfer limitations due to the lack of stirring. In fact, according to our experiments, the variation of the GVL yield with the catalyst mass is not linear.

\section{Conclusions}

Metallic nickel derived from $\mathrm{NiO}$ synthesized by a nanocasting route presents a relatively high yield and selectivity to $\gamma$-valerolactone (up to $40 \%$ and $>98 \%$, respectively) in the transformation of levulinic acid, employing an easy hydrothermal method with water as a solvent at $180^{\circ} \mathrm{C}$. Through this method, the hydrogen proceeds from water and then hydrogenation of levulinic acid is possible. 
The productivity to $\gamma$-valerolactone reached using the nanocasted Ni catalyst is two orders of magnitude higher than that obtained by a commercial nickel catalyst.

Author Contributions: Conceptualization, B.S. and A.M.D.; methodology, T.G., I.V, and F.J.L.; validation, R.S.; experimental, R.S; formal analysis, B.S.; resources, T.G. and A.M.D.; data curation, F.J.L. and I.V.; writing—original draft preparation, B.S.; writing-review and editing, B.S. and T.G.; supervision, B.S.; funding acquisition, B.S. and T.G.

Funding: Authors from UV thank the University of Valencia (UV-INV-AE16-484416 project) and MINECO (MAT2017-84118-C2-1-R project) for funding.

Acknowledgments: Said Agouram and Maria Sales Galletero from SCSIE (Universitat de València) are acknowledged for their help in TEM microscopy and GC-MS measurements.

Conflicts of Interest: The authors declare no conflict of interest.

\section{References}

1. Ragauskas, A.J.; Williams, C.K.; Davison, B.H.; Britovsek, G.; Cairney, J.; Eckert, C.A.; Frederick, W.J., Jr.; Hallett, J.P.; Leak, D.J.; Liotta, C.L. The path forward for biofuels and biomaterials. Science 2006, 311, 484-489. [CrossRef] [PubMed]

2. Serrano-Ruiz, J.C.; West, R.M.; Dumesic, J.A. Catalytic conversion of renewable biomass resources to fuels and chemicals. Annu. Rev. Chem. Biomol. Eng. 2010, 1, 79-100. [CrossRef] [PubMed]

3. Huber, G.W.; Iborra, S.; Corma, A. Synthesis of transportation fuels from biomass: Chemistry catalysts and engineering. Chem. Rev. 2006, 106, 4044-4098. [CrossRef] [PubMed]

4. Bozell, J.J. Connecting biomass and petroleum processing with a chemical bridge. Science 2010, 329, 522-523. [CrossRef] [PubMed]

5. Lin, H.; Strull, J.; Liu, Y.; Karmiol, Z.; Plank, K.; Miller, G.; Guo, Z.; Yang, L. High yield production of levulinic acid by catalytic partial oxidation of cellulose in aqueous media. Energy Environ. Sci. 2012, 5, 9773-9777. [CrossRef]

6. Upare, P.P.; Lee, J.-M.; Hwang, D.W.; Halligudi, S.B.; Hwang, Y.K.; Chang, J.-S. Selective hydrogenation of levulinic acid to $\gamma$-valerolactone over carbon supported noble metal catalysts. Ind. Eng. Chem. Res. 2011, 17, 287-292. [CrossRef]

7. Putrakumar, B.; Nagaraju, N.; Kumar, V.P.; Chary, K.V.R. Hydrogenation of levulinic acid to $\gamma$-valerolactone over copper catalysts supported on $\gamma$-Al2O3. Catal. Today 2015, 250, 209-217. [CrossRef]

8. Bond, J.Q.; Alonso, D.M.; Wang, D.; West, R.M.; Dumesic, J.A. Integrated catalytic conversion of valerolactone to liquid alkenes for transportation fuels. Science 2010, 327, 1110-1114. [CrossRef] [PubMed]

9. Horvath, I.T.; Mehdi, H.; Fabos, V.; Boda, L.; Mika, L.T. $\gamma$-Valerolactone-a sustainable liquid for energy and carbon-based chemicals. Green Chem. 2008, 10, 238-242. [CrossRef]

10. Dutta, S.; Yu, I.K.M.; Tsang, D.C.W.; Ng, Y.H.; Ok, Y.S.; Sherwood, J.; Clark, J.H. Green synthesis of gamma-valerolactone (GVL) through hydrogenation of biomass-derived levulinic acid using non-noble metal catalysts: A critical review. Chem. Engineering J. 2019, 372, 992-1006. [CrossRef]

11. Alonso, D.M.; Wettstein, S.G.; Dumesic, J.A. $\gamma$-valerolactone, a sustainable platform molecule derived from lignocellulosic biomass. Green Chem. 2013, 15, 584-595. [CrossRef]

12. Zhang, J.; Chen, J.; Guo, Y.; Chen, L. Effective Upgrade of Levulinic Acid into $\gamma$-Valerolactone over an Inexpensive and Magnetic Catalyst Derived from Hydrotalcite Precursor. ACS Sustain. Chem. Eng. 2015, 3, 1708-1714. [CrossRef]

13. Yan, K.; Lafleur, T.; Jarvis, C.; Wu, G. Clean and selective production of $\gamma$-valerolactone from biomass-derived levulinic acid catalyzed by recyclable Pd nanoparticle catalyst. J. Clean. Prod. 2014, 72, 230-232. [CrossRef]

14. Yan, K.; Lafleur, T.; Wu, G.; Liao, J.; Ceng, C.; Xie, X. Highly selective production of value added $\gamma$-valerolactone from biomass-derived levulinic acid using the robust Pd nanoparticles. Appl. Catal. A Gen. 2013, 468, 52-58. [CrossRef]

15. Ortiz-Cervantes, C.; García, J.J. Hydrogenation of levulinic acid to $\gamma$-valerolactone using ruthenium nanoparticles. Inorg. Chim. Acta 2013, 397, 124-128. [CrossRef]

16. Du, X.; Liu, Y.; Wang, J.; Cao, Y.; Fan, K. Catalytic conversion of biomass-derived levulinic acid into $\gamma$-valerolactone using iridium nanoparticles supported on carbon nanotubes. Chin. J. Catal. 2013, 34, 993-1001. [CrossRef] 
17. Luo, W.; Sankar, M.; Beale1, A.M.; He, Q.; Kiely, C.J.; Bruijnincx, P.C.A.; Weckhuysen, B.M. High performing and stable supported nano-alloys for the catalytic hydrogenation of levulinic acid to g-valerolactone. Nat. Commun. 2015, 6, 6540. [CrossRef]

18. Cao, S.; Monnier, J.R.; Williams, C.T.; Diao, W.J.; Regalbuto, J.R. Rational nanoparticle synthesis to determine the effects of size, support, and $\mathrm{K}$ dopant on $\mathrm{Ru}$ activity for levulinic acid hydrogenation to gammavalerolactone. J. Catal. 2015, 326, 69-81. [CrossRef]

19. Cao, S.; Monnier, J.R.; Regalbuto, J.R. Alkali promotion of alumina-supported ruthenium catalysts for hydrogenation of levulinic acid to c-valerolactone. J. Catal. 2017, 347, 72-78. [CrossRef]

20. Luo, W.; Deka, U.; Beale, A.M.; van Eck, E.R.H.; Bruijnincx, P.C.A.; Weckhuysen, B.M. Ruthenium-catalyzed hydrogenation of levulinic acid: influence of the support and solvent on catalyst selectivity and stability. J. Catal. 2013, 301, 175-186. [CrossRef]

21. Obregón, I.; Corro, E.; Izquierdo, U.; Requies, J.; Arias, P.L. Levulinic acid hydrogenolysis on Al2O3-based Ni-Cu bimetallic catalysts. Chin. J. Catal. 2014, 35, 656-662.

22. Ishikawa, S.; Jones, D.R.; Iqbal, S.; Reece, C.; Morgan, D.J.; Willock, D.J.; Miedziak, P.J.; Bartley, J.K.; Edwards, J.K.; Murayama, T.; et al. Identification of the catalytically active component of $\mathrm{Cu}-\mathrm{Zr}-\mathrm{O}$ catalyst for the hydrogenation of levulinic acid to $\gamma$-valerolactone. Green Chem. 2017, 19, 225-236. [CrossRef]

23. Orlowski, I.; Douthwaite, M.; Iqbal, S.; Hayward, J.S.; Davies, T.E.; Bartley, J.K.; Miedziak, P.J.; Hirayama, J.; Morgan, D.J.; Willock, D.J.; et al. The hydrogenation of levulinic acid to $\gamma$-valerolactone over $\mathrm{Cu}-\mathrm{ZrO} 2$ catalysts prepared by a pH-gradient methodology. J. Energy Chem. 2019, 36, 15-24. [CrossRef]

24. Ouyang, W.; Zhao, D.; Wang, Y.; Balu, A.M.; Len, C.; Luque, R. Continuous Flow Conversion of Biomass-Derived Methyl Levulinate into $\gamma$-Valerolactone Using Functional Metal Organic Frameworks. ACS Sustain. Chem. Eng. 2018, 6, 6746-6752. [CrossRef]

25. Valekar, A.H.; Cho, K.-H.; Chitale, S.K.; Hong, D.-Y.; Cha, G.-Y.; Lee, U.-H.; Hwang, D.W.; Serre, C.; Chang, J.-S.; Hwang, Y.K. Catalytic transfer hydrogenation of ethyl levulinate to $\gamma$-valerolactone over zirconium-based metal-organic frameworks. Green Chem. 2016, 18, 4542-4552. [CrossRef]

26. Shimizu, K.; Kanno, S.; Kon, K. Hydrogenation of levulinic acid to -valerolactone by Ni and MoOx co-loaded carbon catalysts. Green Chem. 2014, 16, 3899-3903. [CrossRef]

27. Hengst, K.; Schubert, M.; Carvalho, H.W.P.; Lu, C.; Kleist, W.; Grunwaldt, J. Synthesis of $\gamma$-valerolactone by hydrogenation of levulinic acid over supported nickel catalysts. Appl. Catal. A 2015, 502, 18-26. [CrossRef]

28. Mohan, V.; Venkateshwarlu, V.; Pramod, C.V.; Raju, B.D.; Rao, K.S.R. Vapour phase hydrocyclisation oflevulinic acid to -valerolactone over supported catalysts. Catal. Sci. Technol. 2014, 4, 1253-1259. [CrossRef]

29. Lv, J.; Rong, Z.; Wang, Y.; Xiu, J.; Wang, Y.; Qu, J. Highly efficient conversion of biomass-derived levulinic acid into -valerolactone over Ni/MgO catalyst. RSC Adv. 2015, 5, 72037-72045. [CrossRef]

30. Jie, F.; Dong, S.; Xiuyang, L. Hydrogenation of Levulinic Acid over Nickel Catalysts Supported on Aluminum Oxide to Prepare -Valerolactone. Catalysts 2016, 6, 6.

31. Enumula, S.S.; Gurram, V.R.B.; Kondeboina, M.; Burri, D.R.; Kamaraju, S.R.R. ZrO2/SBA-15 as an efficient catalyst for the production of $\gamma$-valerolactone from biomass derived levulinic acid in the vapour phase at atmospheric pressure. RSC Adv. 2016, 6, 20230-20239. [CrossRef]

32. Hengne, A.M.; Rode, C.V. Cu-ZrO2 nanocomposite catalyst for selective hydrogenation of levulinic acid and its ester to $\gamma$-valerolactone. Green Chem. 2012, 14, 1064-1072. [CrossRef]

33. Yuan, J.; Li, S.-S.; Yu, L.; Liu, Y.M.; Cao, Y.; He, H.-Y.; Fan, K.-N. Copper-based catalysts for the efficient conversion of carbohydrate biomass into $\gamma$-valerolactone in the absence of externally added hydrogen. Energy Environ. Sci. 2013, 6, 3308-3313. [CrossRef]

34. Liu, J.; Zeng, X.; Cheng, M.; Yun, J.; Li, Q.; Jing, Z.; Jin, F. Reduction of formic acid to methanol under hydrothermal conditions in the presence of $\mathrm{Cu}$ and Zn. Bioresour. Technol. 2012, 114, 658-662. [CrossRef] [PubMed]

35. Jin, F.; Gao, Y.; Jin, Y.; Zhang, Y.; Cao, J.; Wei, Z.; Smith, R.L., Jr. High-yield reduction of carbon dioxide into formic acid by zerovalent metal/metal oxide redox cycles. Energy Environ. Sci. 2011, 4, 881-884. [CrossRef]

36. Jin, F.M.; Zeng, X.; Liu, J.K.; Jin, Y.J.; Wang, L.Y.; Zhong, H.; Yao, G.D.; Huo, Z.B. Highly efficient and autocatalytic $\mathrm{H} 2 \mathrm{O}$ dissociation for $\mathrm{CO}_{2}$ reduction into formic acid with zinc. Sci. Rep. 2015, 4, 1-8. [CrossRef] [PubMed] 
37. Heng, Z.; Qiuju, L.; Jianke, L.; Guodong, Y.; Jie, W.; Xu, Z.; Zhibao, H.; Fangming, J. New Method for Highly Efficient Conversion of Biomass-Derived Levulinic Acid to $\gamma$-Valerolactone in Water without Precious Metal Catalysts. ACS Sustain. Chem. Eng. 2017, 5, 6517-6523.

38. Scheffer, B.; Molhoek, P.; Moulijn, J.A. Temperature-programmed reduction of $\mathrm{NiO}-\mathrm{WO}_{3} / \mathrm{Al}_{2} \mathrm{O}_{3}$ Hydrodesulphurization catalysts. Appl. Catal. 1989, 46, 11-30. [CrossRef]

39. Li, C.; Chen, Y.W. Temperature-programmed-reduction studies of nickel oxide/alumina catalysts: effects of the preparation method. Thermochim. Acta 1995, 256, 457-465. [CrossRef]

40. Jiang, K.; Sheng, D.; Zhang, Z.; Fu, J.; Hou, Z.; Lu, X. Hydrogenation of levulinic acid to $\gamma$-valerolactone in dioxane over mixed $\mathrm{MgO}-\mathrm{Al}_{2} \mathrm{O}_{3}$ supported $\mathrm{Ni}$ catalyst. Catal. Today 2016, 274, 55-59. [CrossRef]

41. Zhang, B.; Wang, S.; Ma, Z.; Qiu, Y. $\mathrm{Ni}^{0}$-rich $\mathrm{Ni} / \mathrm{NiO}$ nanocrystals for efficient water-to-hydrogen conversion via urea electro-oxidation. Appl. Surf. Sci. 2019, 496, 143710. [CrossRef]

42. Zhu, X.; Dou, X.; Dai, J.; An, X.; Guo, Y.; Zhang, L.; Tao, S.; Zhao, J.; Chu, W.; Zeng, X.C.; et al. Metallic nickel hydroxide Nanosheets give superior Electrocatalytic oxidation of urea for fuel cells. Angew. Chem. Int. Ed. 2016, 55, 12465-12469. [CrossRef] [PubMed]

(C) 2019 by the authors. Licensee MDPI, Basel, Switzerland. This article is an open access article distributed under the terms and conditions of the Creative Commons Attribution (CC BY) license (http://creativecommons.org/licenses/by/4.0/). 